\title{
The Effect of Different Doses of Oral Salinomycin on Oxidative Stress Biomarkers in Sheep
}

\author{
Ali Hajimohammadi ${ }^{1}$, Hameed Rajaian ${ }^{2}$, Somayeh Jafari ${ }^{3}$ and Saeed Nazifi ${ }^{1^{*}}$ \\ ${ }^{1}$ Department of Clinical Studies, School of Veterinary Medicine, Shiraz University, Shiraz, Iran \\ ${ }^{2}$ Department of Basic Sciences, School of Veterinary Medicine, Shiraz University, Shiraz, Iran \\ ${ }^{3}$ Graduate of School of Veterinary Medicine, Shiraz University, Shiraz, Iran
}

*Corresponding author: Saeed Nazifi, Department of Clinical Studies, School of Veterinary Medicine, Shiraz University, Shiraz-71345-1731, Iran, Tel: 98 711 2286 950; E-mail: nazifi@shirazu.ac

Rec date: Apr 24, 2015; Acc date: Jul 25, 2015; Pub date: Jul 27, 2015

Copyright: (C) 2015 Hajimohammadi A, et al. This is an open-access article distributed under the terms of the Creative Commons Attribution License, which permits unrestricted use, distribution, and reproduction in any medium, provided the original author and source are credited.

\begin{abstract}
Salinomycin is a substance which is able to transport particular substance with antimicrobial properties. It is a dietary additive used as a growth promoter for ruminants and as a Veterinary Medicine in chickens. However, over dosage or misuse situations can lead to a series of toxic syndromes. The purpose of this study is to propose the alteration of oxidative stress markers during experimental toxicosis with salinomycin in sheep. Twenty Iranian mixed breed adult female fat-tailed sheep (BW: $36 \pm 3.5 \mathrm{~kg}$ ) were used in this study. Sheep were randomly divided into five equal groups. Group I (control) received $20 \mathrm{ml}$ normal saline. Groups II, III, IV and V were orally administered 1 $\mathrm{mg} / \mathrm{kg}$ (twice a day for two days), 2, 3 and $4 \mathrm{mg} / \mathrm{kg}$ (once a day for two days) salinomycin, respectively. Following drug administration, blood samples were collected at different time intervals (2, 5, 8, 14 and 21 days) in order to determine oxidative stress markers, SOD, GPX, Catalase, and MDA were measured using validated standard methods. The results indicated a significant decrease in SOD, GPX and Catalase, and an increase in MDA in salinomycin treated groups compared to control group $(\mathrm{P}<0.05)$. In addition, salinomycin induced significant decrease in the concentration of vitamin $C$. Concentrations of vitamin $A$ and vitamin $E$ were also increased, but the increase was not significant. The interaction between times and groups was significant with respect to all vitamins. In conclusion salinomycin intoxication in sheep can cause oxidative stress.
\end{abstract}

Keywords: Salinomycin; Oxidative stress; Biomarkers; Sheep Vitamins; Antioxidants

\section{Introduction}

Oxidative stress is a term relative to the elevated levels of reactive free radicals in an organism. Oxidative stress can occur from diminished antioxidants and/or increased production of reactive free radicals. The increased production of free radicals is more relevant to disease and frequently the attempted target of supplementation intervention. In many instances the body can adapt to an increase in oxidative stress by up regulation of antioxidant defense systems. If the oxidative stress can be neutralized, there is often no adverse contribution to disease pathology $[1,2]$. If the antioxidant defense induction is inadequate or nonexistent then accompanying cellular and tissue damage often occurs. Some diseases can be caused directly by oxidative stress, however, in most diseases oxidative stress is a consequence and may often only be a secondary event. It does, however, play an important role in promoting additional tissue injury in most diseases. On the other hand, oxidative stress may have beneficial effects in activating biological pathways that alter antioxidant defenses and allow an organism to adapt. Oxidative stress is also considered necessary to promote healing and repair of tissues. Therefore, not all cases of oxidative stress are damaging. Only when oxidative stress is inappropriate that it is excessive and addressed with supplementation and antioxidant therapy that reduces oxidative damage to cells, tissues, proteins, cellular membranes, and mitochondria [3].
Ionophore antibiotics are fermentation products of various Streptomyces spp. (monensin, salinomycin) and Actinomadura spp. (maduramycin) [4]. They function as mobile cation carriers and have the ability to complex with and transport organic amines $[5,6]$. Carboxylic ionophores are prevalent growth promoters for ruminants as well as being widely used as anticoccidial drugs for poultry; however, over dosage can lead to a series of toxic syndromes [7-10]. Ionophores toxicity varies considerably among species. Toxicity may occur after accidental access to medicated feed, errors in feed mixing, deliberate feeding of a ration formulated for a less sensitive species, and/or concurrent use of some products with known interactions [11]. Experimental salinomycin toxicosis in sheep causes a variety of pathologic changes such as congestion and edema of skeletal muscles, swelling and hemorrhage in peripheral lymph nodes, myocardial degeneration and necrosis, degeneration of centrilobular hepatocytes, acute tubular necrosis of cortical tubules of kidney [12,13]. In farm animals, oxidative stress may be involved in several pathological conditions, including conditions that are relevant for animal production and the general welfare of the individuals. Oxidative damage is result of oxidative modification of cellular macromolecules; cell death by apoptosis or necrosis, as well as structural tissue damage [14], since the role of oxidative stress in salinomycine intoxication has not described this study was performed to evaluate the role of oxidants and antioxidants in this ionophores toxicity in sheep. 


\section{Materials and Methods}

\section{Experimental design}

Twenty mixed breed adult (average one year old) uncastrated male clinically healthy Iranian fat-tailed sheep weighing $36 \pm 3.5 \mathrm{~kg}$ were stable-fed ad libitum with a mixture of alfalfa hay, corn silage and barley grains. Sheep were randomly divided into five equal experimental groups and housed in separate stables. They were weighted before each experiment (sodium salinomycin orally administered). Group one (control) received $20 \mathrm{ml}$ distilled water with stomach tube. Groups II, III, IV and V were orally with stomach tube, administered 1,2, 3 and $4 \mathrm{mg} / \mathrm{kg}$ (twice a day) sodium salinomycin, respectively. Following drug administration, the clinical signs of sheep in all groups were carefully monitored and blood samples were collected from jugular vein at different time intervals $(2,5,8,11$ and 17 days) in order to examine variables related to the oxidative stress parameters. One sheep from group $4(3 \mathrm{mg} / \mathrm{kg})$, and one sheep from group $5(4 \mathrm{mg} / \mathrm{kg})$ died within $48 \mathrm{~h}$ after the administration of salinomycin and different samples were taken as biopsy from the dead animals for histopathology examination. The sera were separated by centrifugation at $750 \mathrm{~g}$ for $15 \mathrm{~min}$ and were kept at $-20^{\circ} \mathrm{C}$ until analysis.

\section{Animal ethics}

This experiment was accomplished under the approval of the State Committee on Animal Ethics, Shiraz University, Shiraz, Iran. The recommendations of European Council Directive (86/609/EC) of November 24, 1986 regarding the standards in the protection of animals used for experimental purposes were also followed.

\section{Measurements}

Blood and hemoglobin preparation: The heparinized blood was centrifuged to remove plasma components. The packed red cells were washed three times in an isotonic saline solution $(0.9 \% \mathrm{NaCl})$ and red cells were osmetically lysed with cold distilled water (2 cc). Hemoglobin $(\mathrm{Hb})$ was measured using cyanmethemoglobin method [15].

Superoxide dismutase (SOD) assay: Blood SOD activity was evaluated with SOD detection RANSOD kit (Randox lab. Crumlin United Kingdom) according to the manufacturer's instructions. The role of SOD is to accelerate the dismutation of the toxic superoxide produced during oxidative energy processes to hydrogen peroxide and molecular oxygen. This method employs xanthine and xanthine oxidase (XOD) to generate superoxide radicals which react with 2-(4iodophenyl)-3-(4-nitrophenol)-5-phenyltetrazolium chloride (INT) to form a red formazan dye. The SOD activity is then measured by the degree of inhibition of this reaction. One unit of SOD is that which causes $50 \%$ inhibition of the rate of reduction of INT under the conditions of the assay. SOD levels were recorded at $505 \mathrm{~nm}$ and through a standard curve and expressed unit per gram of hemoglobin $(\mathrm{U} / \mathrm{g} \mathrm{Hb})$.

Glutathione peroxidase (GPX) assay: The activity of GPX was evaluated with GPx detection RANSEL kit (Randox lab. Crumlin United Kingdom) according to the manufacturer's instructions. GPX catalyze the oxidation of glutathione (GSH) by cumene hydroperoxide. In the presence of glutathione reductase (GR) and NADPH, the oxidized glutathione (GSSG) is immediately converted to the reduced form with a concomitant oxidation of NADPH to NADP+. The decrease in absorbance at $340 \mathrm{~nm}$ against blank was measured spectrophotometrically. One unit (U) of GPX activity was defined as the amount of enzyme that converts $1 \mu \mathrm{mol}$ of NADPH to NADP+ per minute. The GPX activity was expressed as unit per gram of hemoglobin $(\mathrm{U} / \mathrm{gHb})$.

Catalase (CAT) assay: Blood catalase activity was assayed spectrophotometrically by monitoring the decomposition of $\mathrm{H}_{2} \mathrm{O}_{2}$ using the procedure of Aebi [16]. Briefly, $0.5 \mathrm{~mL}$ of $30 \mathrm{mmol} / \mathrm{L} \mathrm{H}_{2} \mathrm{O}_{2}$ solution in $50 \mathrm{mmol} / \mathrm{L}$ phosphate buffer $(\mathrm{pH}=7.0), 1 \mathrm{~mL}$ of $1: 10$ diluted erythrocyte lysates was added and the consumption of $\mathrm{H}_{2} \mathrm{O}_{2}$ was followed spectrophotometrically at $240 \mathrm{~nm}$ for $2 \mathrm{~min}$ at $25^{\circ} \mathrm{C}$. The molar extinction coefficient was $43.6 \mathrm{~L} / \mathrm{mol}$ per $\mathrm{cm}$ for $\mathrm{H}_{2} \mathrm{O}_{2}$. Catalase activity was expressed as the unit that is defined as $\mu$ mol $\mathrm{H}_{2} \mathrm{O}_{2}$ consumed/min per gram hemoglobin.

\section{Measurement of lipid peroxidation (MDA)}

To evaluate lipid peroxidation in blood a modified HPLC method was used that is based on the reaction of malondialdehyde (MDA) with thiobarbituric acid (TBA) to form a coloured MDA-TBA adduct [17]. Briefly, $0.5 \mathrm{~mL}$ blood supernatant was added to $2 \mathrm{~mL}$ TBA reagent containing $0.375 \%$ TBA, $15 \%$ trichloroacetic acid and 0.25 $\mathrm{mol} / \mathrm{L} \mathrm{HCl}$. The mixture was immediately heated $\left(60 \mathrm{~min}\right.$ at $\left.95^{\circ} \mathrm{C}\right)$ and cooled with running water, and thereafter butanol-pyridine $(15: 1, \mathrm{v} / \mathrm{v})$ $(1 \mathrm{~mL})$ was added and the final volume was adjusted to $2 \mathrm{~mL}$ with distilled water. After vigorous mixing, the organic layer was separated by centrifugation $(16,000 \mathrm{~g}, 3$ minutes, at room temperature). The supernatant was analyzed on a UV-visible spectrophotometer fitted with an $80 \mu \mathrm{L}$ flow cell $[6,18]$. The absorbance was measured at 532 $\mathrm{nm}$ (the mobile phase consisted of $300 \mathrm{~mL} / \mathrm{L}$ methanol in $50 \mathrm{mM}$ $\mathrm{KH}_{2} \mathrm{PO}_{4}, \mathrm{pH}$ : 7.0). 1, 1, 3, 3-tetraethoxypropane was used as a standard, and MDA-TBA reactive substances values were expressed as Unit per gram of hemoglobin (U/g hemoglobin). The HPLC system consisted of a solvent delivery pump (JASCO 980-PU, Tokyo, Japan), a reversed-phase column (Luna C18, $250 \mathrm{~mm} \times 4.6 \mathrm{~mm}$, Phenomenex, CA, USA), and a UV-Vis detector (Jasco, UV-975, Tokyo, Japan) operated at $532 \mathrm{~nm}$.

\section{Statistical analysis}

Data were analyzed by analysis of variance (one-way ANOVA and repeated measurements ANOVA) using SAS Systems for Windows release 9.11 computer software (SAS Institute Inc., Cary, NC). The significance of differences in means between the groups was evaluated by Duncan test. Significance level was set to be $\mathrm{P}<0.05$. The values are represented as the mean \pm SEM.

\section{Results}

\section{Clinical Signs}

After oral administration of salinomycin the Clinical signs noticed were inappetence, non-coordination, dehydration, expanded breath, tachycardia, muscular weakness, salivation, persistent gasping, prostration and paralysis, groan, tremors, increased body temperature and heart rate, oral and nasal discharge and bruxism. Advanced clinical signs in sheep that later died included severe tachycardia and tachypnea associated with hind limb ataxia. One sheep from group 2 $(1 \mathrm{mg} / \mathrm{kg})$, and one sheep from group $5(4 \mathrm{mg} / \mathrm{kg})$, died within $72 \mathrm{~h}$ after the administration of salinomycin 
Citation: Hajimohammadi A, Rajaian H, Jafari S, Nazifi S (2015) The Effect of Different Doses of Oral Salinomycin on Oxidative Stress

Page 3 of 6

\section{Pathology}

Postmortem examination revealed congestion and edema of skeletal muscles, swelling and hemorrhagic foci in peripheral lymph nodes, hydrothorax and hydropericardium, petechial hemorrhage in fat tissues of heart base on epicardium, severe pulmonary congestion and edema, and also the presence of moderate frothy fluid in trachea and bronchi. In the heart muscle, myocardial degeneration and necrosis without any inflammatory reaction or calcification and epicardial hemorrhage within deposited fat cells were diagnosed.

\section{Biochemical parameters}

Various degrees of changes in several biochemical parameters during 5 consecutive days in all these groups are demonstrated in Table 1.

\begin{tabular}{|c|c|c|c|c|c|}
\hline \multirow{2}{*}{ Group } & \multirow{2}{*}{$\begin{array}{l}\text { Time } \\
\text { intervals }\end{array}$} & SOD $^{*}$ & GPX & Catalase $^{*}$ & $\mathrm{MDA}^{*}$ \\
\hline & & $(\mathrm{U} / \mathrm{gHb})$ & $(\mathrm{U} / \mathrm{gHb})$ & ( U/gHb) & ( Umol/L) \\
\hline \multirow{6}{*}{$\begin{array}{l}\text { Group I } \\
\text { (Control) }\end{array}$} & 2 & $1383.7 \pm 115.4$ & $244.8 \pm 9.7$ & $1768.2 \pm 210.6$ & $0.95 \pm 0.03$ \\
\hline & 5 & $1275.0 \pm 24.4$ & $213.1 \pm 11.9$ & $1965.2 \pm 153.5$ & $1.09 \pm 0.01$ \\
\hline & 8 & $1182.5 \pm 45.3$ & $230.3 \pm 11.4$ & $1817.5 \pm 161.6$ & $1.03 \pm 0.06$ \\
\hline & 11 & $1337.5 \pm 93.0$ & $244.9 \pm 12.3$ & $1825.5 \pm 221.7$ & $1.00 \pm 0.03$ \\
\hline & 17 & $1206.2 \pm 37.1$ & $234.5 \pm 8.7$ & $1778.7 \pm 169.3$ & $0.86 \pm 0.08$ \\
\hline & 2 & $1297.5 \pm 94.0$ & $186.9 \pm 14.5$ & $1655.0 \pm 188.2$ & $1.08 \pm 0.04$ \\
\hline \multirow{4}{*}{$\begin{array}{l}\text { Group II } \\
(1 \mathrm{mg} / \mathrm{kg})\end{array}$} & 5 & $1145.0 \pm 49.8$ & $179.6 \pm 8.1$ & $1839.2 \pm 154.9$ & $1.14 \pm 0.04$ \\
\hline & 8 & $1136.2 \pm 49.9$ & $173.3 \pm 9.6$ & $1708.0 \pm 141.6$ & $1.09 \pm 0.03$ \\
\hline & 11 & $1100.0 \pm 29.4$ & $164.7 \pm 12.7$ & $1690.2 \pm 199.2$ & $1.10 \pm 0.03$ \\
\hline & 17 & $1137.5 \pm 44.5$ & $162.4 \pm 12.5$ & $1638.0 \pm 167.6$ & $1.09 \pm 0.04$ \\
\hline \multirow{6}{*}{$\begin{array}{l}\text { Group III } \\
(2 \mathrm{mg} / \mathrm{kg})\end{array}$} & 2 & $1052.0 \pm 30.1$ & $158.1 \pm 14.5$ & $1539.5 \pm 169.2$ & $1.11 \pm 0.02$ \\
\hline & 5 & $1000.0 \pm 43.8$ & $134.6 \pm 10.3$ & $1699.0 \pm 151.3$ & $1.13 \pm 0.00$ \\
\hline & 8 & $986.2 \pm 36.4$ & $132.1 \pm 11.4$ & $1625.7 \pm 146.1$ & $1.14 \pm 0.02$ \\
\hline & 11 & $1033.7 \pm 31.3$ & $145.1 \pm 8.3$ & $1614.5 \pm 167.4$ & $1.12 \pm 0.02$ \\
\hline & 17 & $987.5 \pm 46.2$ & $129.7 \pm 9.7$ & $1531.7 \pm 174.5$ & $1.18 \pm 0.01$ \\
\hline & 2 & $800.0 \pm 12.4$ & $119.7 \pm 7.1$ & $1469.2 \pm 176.3$ & $1.30 \pm 0.04$ \\
\hline \multirow{5}{*}{$\begin{array}{l}\text { Group IV } \\
\text { (3 mg/kg) }\end{array}$} & 5 & $828.7 \pm 67.7$ & $132.6 \pm 10.0$ & $1334.7 \pm 171.8$ & $1.26 \pm 0.07$ \\
\hline & 8 & $798.7 \pm 25.4$ & $126.1 \pm 9.6$ & $1598.7 \pm 147.9$ & $1.19 \pm 0.05$ \\
\hline & 11 & $815.0 \pm 57.8$ & $131.1 \pm 8.2$ & $1513.5 \pm 127.1$ & $1.24 \pm 0.05$ \\
\hline & 17 & $780.0 \pm 29.2$ & $118.4 \pm 6.1$ & $1533.5 \pm 186.8$ & $1.26 \pm 0.02$ \\
\hline & 2 & $738.7 \pm 28.4$ & $115.8 \pm 7.1$ & $1435.5 \pm 159.8$ & $1.34 \pm 0.05$ \\
\hline \multirow{4}{*}{$\begin{array}{l}\text { Group V } \\
\text { (4 mg/kg) }\end{array}$} & 5 & $696.2 \pm 44.4$ & $113.9 \pm 5.3$ & $1468.0 \pm 112.0$ & $1.31 \pm 0.02$ \\
\hline & 8 & $686.2 \pm 18.2$ & $126.7 \pm 5.1$ & $1431.2 \pm 119.7$ & $1.33 \pm 0.04$ \\
\hline & 11 & $685.0 \pm 35.2$ & $113.4 \pm 4.3$ & $1378.2 \pm 179.8$ & $1.31 \pm 0.02$ \\
\hline & 17 & $693.7 \pm 38.5$ & $116.6 \pm 6.2$ & $1330.7 \pm 159.2$ & $1.31 \pm 0.01$ \\
\hline
\end{tabular}

Table 1: Blood SOD, GPX, Catalase and MDA after oral administration of various doses of salinomycin in sheep. * Significant difference between control and other groups at $\mathrm{P}<0.05$.

\section{SOD}

There was significant decrease in SOD in different times in all groups but the interaction between times and groups were not significant. It indicated that the trend of changes in all groups was the same. 
Page 4 of 6

\section{GPX}

There was significant decrease in GPX in all salinomycin treated groups' compared to control group, but no significant differences were observed in different times, also the interaction between times and groups was not significant after salinomycin intoxications.

\section{Catalase}

Significant decrease was observed in catalase in all salinomycin treated groups' compared to control group, but no significant differences were observed in different times, also the interaction between times and groups was not significant after salinomycin intoxications, which indicated that the trend of changes in all groups was the same.

\section{MDA}

Significant increase was observed in MDA in salinomycin treated groups compared to control group $(\mathrm{P}<0.001)$ but no significant differences were observed in different times, also the interaction between times and groups was not significant after salinomycin intoxications, which indicated that the trend of changes in all groups was the same.

\section{Vitamin A}

Vitamin A concentration was increased, but the increase was not significant. Significant differences were observed in different times, also the interaction between times and groups were significant after salinomycin intoxications. It indicated that the trend of changes in all groups was not the same. These are shown in Table 2.

\begin{tabular}{|c|c|c|c|c|}
\hline \multirow{2}{*}{ Group } & \multirow{2}{*}{$\begin{array}{l}\text { Time } \\
\text { interval } \\
\mathbf{s}\end{array}$} & Vitamin $A^{*}$ & Vitamin $E^{*}$ & Vitamin $C^{*}$ \\
\hline & & (microg/dl) & (microg/ml) & $(\mathrm{mmol} / \mathrm{ml})$ \\
\hline \multirow{6}{*}{$\begin{array}{l}\text { Group I } \\
\text { (Control) }\end{array}$} & 2 & $27.0 \pm 0.1 \mathrm{a}$ & $0.89 \pm 0.01 c$ & $0.25 \pm 0.04$ \\
\hline & 5 & $26.9 \pm 0.4 a$ & $0.72 \pm 0.09 b$ & $0.26 \pm 0.00$ \\
\hline & 8 & $22.7 \pm 0.8 b$ & $0.75 \pm 0.02 b$ & $0.63 \pm 0.14$ \\
\hline & 11 & $26.2 \pm 1.3 a$ & $0.63 \pm 0.05 a$ & $0.56 \pm 0.04$ \\
\hline & 17 & $29.8 \pm 1.4 \mathrm{c}$ & $0.97 \pm 0.03 c$ & $0.25 \pm 0.01$ \\
\hline & 2 & $26.4 \pm 0.3 a$ & $0.89 \pm 0.07 c$ & $0.53 \pm 0.02$ \\
\hline \multirow{4}{*}{$\begin{array}{l}\text { Group II } \\
\text { (1 mg/kg) }\end{array}$} & 5 & $29.8 \pm 0.2 c$ & $0.88 \pm 0.01 c$ & $0.16 \pm 0.02$ \\
\hline & 8 & $24.6 \pm 0.7 a$ & $0.80 \pm 0.06 b$ & $0.10 \pm 0.03$ \\
\hline & 11 & $26.6 \pm 2.1 \mathrm{a}$ & $0.62 \pm 0.07 a$ & $0.05 \pm 0.00$ \\
\hline & 17 & $29.9 \pm 1.5 c$ & $0.99 \pm 0.04 c$ & $0.08 \pm 0.03$ \\
\hline \multirow{6}{*}{$\begin{array}{l}\text { Group III } \\
(2 \mathrm{mg} / \mathrm{kg})\end{array}$} & 2 & $25.1 \pm 0.3 a$ & $0.89 \pm 0.03 c$ & $0.89 \pm 0.28$ \\
\hline & 5 & $29.9 \pm 0.3 c$ & $0.70 \pm 0.06 b$ & $0.08 \pm 0.02$ \\
\hline & 8 & $25.9 \pm 0.7 a$ & $0.88 \pm 0.02 c$ & $0.16 \pm 0.10$ \\
\hline & 11 & $29.5 \pm 1.7 c$ & $0.63 \pm 0.05 a$ & $0.23 \pm 0.17$ \\
\hline & 17 & $30.0 \pm 1.0 \mathrm{c}$ & $0.99 \pm 0.09 c$ & $0.12 \pm 0.06$ \\
\hline & 2 & $25.5 \pm 0.1 a$ & $0.80 \pm 0.03 b$ & $0.62 \pm 0.04$ \\
\hline
\end{tabular}

\begin{tabular}{|l|l|l|l|l|}
\hline \multirow{4}{*}{$\begin{array}{l}\text { Group IV } \\
(3 \mathrm{mg} / \mathrm{kg})\end{array}$} & 5 & $29.7 \pm 0.1 \mathrm{c}$ & $0.75 \pm 0.06 \mathrm{~b}$ & $0.23 \pm 0.07$ \\
\cline { 2 - 5 } & 8 & $26.3 \pm 0.4 \mathrm{a}$ & $0.57 \pm 0.06 \mathrm{a}$ & $0.08 \pm 0.04$ \\
\cline { 2 - 5 } & 11 & $23.9 \pm 0.6 \mathrm{~b}$ & $0.71 \pm 0.16 \mathrm{~b}$ & $0.05 \pm 0.01$ \\
\cline { 2 - 5 } & 17 & $32.3 \pm 0.4 \mathrm{c}$ & $0.75 \pm 0.08 \mathrm{~b}$ & $0.11 \pm 0.03$ \\
\hline \multirow{3}{*}{$\begin{array}{l}\text { Group V } \\
(4 \mathrm{mg} / \mathrm{kg})\end{array}$} & 2 & $25.6 \pm 0.1 \mathrm{a}$ & $0.80 \pm 0.01 \mathrm{~b}$ & $0.31 \pm 0.07$ \\
\cline { 2 - 5 } & 8 & $28.5 \pm 0.1 \mathrm{c}$ & $0.89 \pm 0.24 \mathrm{c}$ & $0.13 \pm 0.05$ \\
\cline { 2 - 5 } & 11 & $28.8 \pm 1.1 \mathrm{c}$ & $0.63 \pm 0.12 \mathrm{a}$ & $0.07 \pm 0.01$ \\
\cline { 2 - 5 } & 17 & $30.4 \pm 1.7 \mathrm{c}$ & $0.80 \pm 0.08 \mathrm{~b}$ & $0.13 \pm 0.02$ \\
\hline
\end{tabular}

Table 2: Blood antioxidant vitamins, vitamin A, vitamin $\mathrm{E}$ and vitamin $\mathrm{C}$ after oral administration of various doses of salinomycin in sheep. *Significant difference between controls and other groups and small different letters show significant difference between various times of experiment in each group $(\mathrm{P}<0.05)$.

\section{Vitamin E}

Vitamin E concentration was increased in salinomycin treated groups, but this increase was not significant. Significant differences were observed in different times but the interaction between times and groups were not significant, which indicated that the trend of changes in all groups was the same.

\section{Vitamin C}

Salinomycin induced significant decrease in the concentration of vitamin $\mathrm{C}$ in different times in all groups. The interaction between times and groups was significant, which indicated that the trend of changes in all groups was not the same.

\section{Discussion}

Oxidative damage is one result of an imbalance between oxidants and antioxidants at the cellular or individual level and includes oxidative modification of cellular macromolecules, cell death by apoptosis ornecrosis, as well as structural tissue damage [14]. In the intoxicated animals with salinomycin structural tissue damage and necrosis in different organs occur; specifically the highly energetic tissues of the body such as myocardium and skeletal muscle are primarily affected $[12,13,19]$. As salinomycin make complexes with cations and mediate their transport across the cell membrane in response to diffusion gradient, mitochondrial failure and depletion of cellular adenosine triphosphate (ATP) may occur. In addition, failure of calcium ion retrieval from the cytosol and, ultimately, myofibril hyper contraction, degeneration and necrosis occur. It should be mentioned that changes in transmembrane ion gradients and electrical potential often produce profound effects on cellular functions and metabolism [20]. The body fights free radicals and oxidant molecules by use of antioxidants such as SOD, GPX and catalase. On the other hand, due to liver damage, production of these enzymes was decreased. This causes a significant decrease in the levels of these antioxidant enzymes in salinomycin intoxicated sheep. It seems that another reason for the decline of these antioxidant enzymes measured in the present study is that the antioxidants SOD, GPX and catalase are members of such antioxidants that are not only used as antioxidant 
agents but also deal with the production of free radicals [21]. The metabolic status of the tissues affects the antioxidant defense system and antioxidant depletion could be the consequence of oxidative stress [22].

In the present study, as the salinomycin intoxication progressed, the activities of SOD and GPX were significantly decreased that indicated increased tissue damage and increased exposure of different organs to oxidative stress products, with consequent loss of the symmetrical structure of lipids in cell membrane, decrease in flexibility, disturbance in water and ion exchange, swallowing and destruction of cells [2,23]. The fragility of cells exposed to oxidants increases. Also, decreased SOD and GPX induce irreversible damage to cell membrane structure and lead to decrease in $\mathrm{O}_{2}$ consumption $[23,24]$. There is a positive correlation between oxidative stress and cells life cycle. The more oxidative stress affects the cells, the less GPX and SOD could play their antioxidant role [25]. SOD and GPX are responsible for cell protection whereby free $\mathrm{O}_{2}$ radicals are converted to hydrogen peroxide by SOD and hydrogen peroxide gets catabolized by GPX [23].

In the current study MDA level was increased in salinomycin treated groups considerably. This finding shows salinomycin intoxication increase levels of lipid peroxidation products. The main target substrates for oxygen radical activity is the polyunsaturated fatty acids that present in membrane phospholipids and result in disorganization of cell framework and function [14].

Lipid peroxidation is one indicator of oxidative stress in cells and tissues. Lipid peroxides derived from polyunsaturated fatty acids are unstable and are decomposed to form a series of compounds, including malondialdehyde (MDA). The quantization of MDA is commonly used to indicate lipid peroxidation [26]. Increased levels of lipid peroxidation products like MDA have been reported in numerous diseases including kidney diseases in dogs [27].

In addition, salinomycin intoxication induced insignificant increases in the concentration of vitamin $\mathrm{A}$ and vitamin $\mathrm{E}$. These vitamins are potent scavengers of free radicals, and support antioxidant function. Vitamins A, E and C may exert their beneficial effects because of their antioxidant, membrane stabilizing, and immunomodulating properties in animals exposed to stresses and infection pressures. Vitamin $\mathrm{E}$ has also been extensively evaluated as an antioxidant micronutrient [28].

Regarding the increased levels of antioxidant vitamins A and $\mathrm{E}$ on the one side and the significant decrease in serum level of vitamin $C$ on the other in salinomycin treated groups, it can be suggested that despite the antioxidant activity of vitamins $\mathrm{A}$ and $\mathrm{E}$, these vitamins could not indicate marked responses to oxidative injuries induced by salinomycin intoxication. In contrast, vitamin $\mathrm{C}$ may indicate a significant role to protect the cells from the invasion of free radicals. It can be proposed that despite cellular protective action of vitamins against oxidative stress as a result of salinomycin toxicity, the increased level of vitamins A and E in our work may be attributed to the occurrence of an equilibrium between the levels of vitamin uptake and their levels in the serum and body tissues, particularly the liver storage which probably has a role in enhancing the decreased serum level of these vitamins in salinomycin intoxicated sheep [29], also as vitamin $\mathrm{A}$ and $\mathrm{E}$ are fat-soluble, these increases might be due to lipid peroxidation in salinomycin toxicity. Although the status of antioxidant vitamins has not been clearly investigated in salinomycin toxicity in sheep, a number of previous studies demonstrated the decreased blood levels of such vitamins in the serum of the affected animals and suggest that this phenomenon was a consequence of elevation in the level of oxidative damages [14,30,31]. It was apparentthat in this study due to salinomycin intoxication in sheep, oxidative molecules increase and protective cellular antioxidants decrease.

The overall picture of the study suggests that salinomycin intoxication can cause oxidative stress and, therefore, supplementation of the patient with high antioxidant may be effective in the reversal of salinomycin toxicity.

\section{References}

1. A-Gubory KH, Fowler PA, Garrel C (2010) The roles of cellular reactive oxygen species, oxidative stress and antioxidants in pregnancy outcomes. Int J Biochem Cell Biol 42: 1634-1650.

2. Glass GA, Gershon D (1984) Decreased enzymic protection and increased sensitivity to oxidative damage in erythrocytes as a function of cell and donor aging. Biochem J 218: 531-537.

3. Mandelker L, Vajdovich P (2011) Studies on Veterinary Medicine. Oxidative stress in applied basic research and clinical practice.

4. Butaye P, Devriese LA, Haesebrouck F (2003) Antimicrobial growth promoters used in animal feed: effects of less well known antibiotics on gram-positive bacteria. Clin Microbiol Rev 16: 175-188.

5. McKellar Q, Lawrence K (1996) lonophores. In Practice 18: 385-386.

6. Zinn RA (1986) Influence of forage level on response of feedlot steers to salinomycin supplementation. J Anim Sci 63: 2005-2012.

7. Galitzer SJ, Bartley EE, Oehme FW (1982) Preliminary studies on lasalocid toxicosis in cattle. Vet Hum Toxicol 24: 406-409.

8. Novilla MN (1992) The veterinary importance of the toxic syndrome induced by ionophores. Vet Hum Toxicol 34: 66-70.

9. Schweitzer D, Kimberling C, Spraker T, Sterner FE, McChesney AE (1984) Accidental monensin sodium intoxication of feedlot cattle. J Am Vet Med Assoc 184: 1273-1276.

10. Wilson JS (1980) Toxic myopathy in a dog associated with the presence of monensin in dry food. Can Vet J 21: 30-31.

11. Roder JD (2011) Ionophore toxicity and tolerance. Vet Clin North Am Food Anim Pract 27: 305-314, viii.

12. Hajimohammadi A, Rajaian H, Khaliji E, Nazifi S, Ansari-Lari M (2014) Serum cardiac troponin I as a biomarker in cardiac degeneration following experimental salinomycin toxicosis in sheep. Veterinarski Arhiv 84: 41-51.

13. Khodakaram Tafti A, Nazifi S, Rajaian H, Sepehrimanesh M, Poorbaghi S, et al. (2008) Pathological changes associated with experimental salinomycin toxicosis in sheep. Comparative Clinical Pathology 17: 255-258.

14. Lykkesfeldt J, Svendsen O (2007) Oxidants and antioxidants in disease: oxidative stress in farm animals. Vet J 173: 502-511.

15. Voigt GL, Swist SL (2013) Hematology techniques and concepts for veterinary technicians. John Wiley \& Sons.

16. Aebi H (1983) Catalase in Methods of Enzymatic Analysis HU Bergmeyer, (3rdedn) Weinheim: Verlag. Chemie 273-286.

17. Lykkesfeldt J (2001) Determination of malondialdehyde as dithiobarbituric acid adduct in biological samples by HPLC with fluorescence detection: comparison with ultraviolet-visible spectrophotometry. Clin Chem 47: 1725-1727.

18. Hagar HH, E Etter E, Arafa M (2006) Taurine attenuates hypertension and renal dysfunction induced by cyclosporine $\mathrm{A}$ in rats. Clin Exp Pharmacol Physiol 33: 189-196.

19. Hosseini R, Rajaian H, Hajimohammadi A, Nazifi S, Khaliji E, et al (2013) ECG alterations and changes in biochemical parameters associated with experimental salinomycin toxicosis in sheep. Iranian Journal of Veterinary Research 14: 120-125. 
Citation: Hajimohammadi A, Rajaian H, Jafari S, Nazifi S (2015) The Effect of Different Doses of Oral Salinomycin on Oxidative Stress Biomarkers in Sheep. J Veterinar Sci Technol 6: 243. doi:10.4172/2157-7579.1000243

Page 6 of 6

20. Fahim M, de Valle G, Pressman BC (1986) Comparison of the effects of the ionophore salinomycin and adrenaline on the haemodynamics and work efficiency of the dog heart. Cardiovasc Res 20: 145-152.

21. Fiers W, Beyaert R, Declercq W, Vandenabeele P (1999) More than one way to die: apoptosis, necrosis and reactive oxygen damage. Oncogene 18: 7719-7730.

22. Venditti P, Di Meo S (2006) Thyroid hormone-induced oxidative stress. Cell Mol Life Sci 63: 414-434.

23. Edwards C, Fuller J (1996) Oxidative stress in erythrocytes. Comparative Hematology International 6: 24-31.

24. Vácha J (1983) Red Cell Life-Span, in: Agar NS, Board PG (Eds): Red Blood Cells of Domestic Mammals. Elsevier/North Holland Biomedical Press, Amsterdam New York Oxford pp: 67-132

25. Saik LA, Hsieh HL, Baricos WH, Shapira E (1982) Enzymatic and immunologic quantitation of erythrocyte superoxide dismutase in adults and in neonates of different gestational ages. Pediatr Res 16: 933-937.

26. Simsek S, Yuce A, Utuk AE (2006) Determination of serum malondialdehyde levels in sheep naturally infected with Dicrocoelium dendriticum. Firat Üniversitesi Saglik Bilimleri Dergisi 20: 217-220.
27. Kargin F, Fidanci UR (2001) Kidney diseases and antioxidative metabolism in dogs. Turkish Journal of Veterinary and Animal Sciences 25: 607-613.

28. Rice-Evans CA, Diplock AT (1993) Current status of antioxidant therapy. Free Radic Biol Med 15: 77-96.

29. Barandier C, Tanguy S, Pucheu S, Boucher F, De Leiris J (1999) Effect of antioxidant trace elements on the response of cardiac tissue to oxidative stress. Ann N Y Acad Sci 874: 138-155.

30. Chen X, Touyz RM, Park JB, Schiffrin EL (2001) Antioxidant effects of vitamins $\mathrm{C}$ and $\mathrm{E}$ are associated with altered activation of vascular NADPH oxidase and superoxide dismutase in stroke-prone SHR. Hypertension 38: 606-611.

31. Heyland DK, Dhaliwal R, Suchner U, Berger MM (2005) Antioxidant nutrients: a systematic review of trace elements and vitamins in the critically ill patient. Intensive Care Med 31: 327-337. 